\title{
Acquired C3 deficiency in patients with alcoholic cirrhosis predisposes to infection and increased mortality
}

\author{
C Homann, K Varming, K Høgåsen, T E Mollnes, N Graudal, Å C Thomsen, P Garred
}

\begin{abstract}
Background-Acquired deficiencies of certain complement proteins and impaired opsonisation activity have been implicated in the pathogenesis of the increased susceptibility to infections of patients with alcoholic cirrhosis.
\end{abstract}

Methods-Serum concentrations of C3 and C4, plasma concentrations of $\mathbf{C} 3 \mathbf{b c}$, C9, and the terminal C5b-9 complement complex (TCC), and haemolytic complement activity (classic and alternative pathway) of serum, and serum opsonic activity were determined in 46 patients with compensated alcoholic cirrhosis, 31 who were decompensated, and in 15 healthy subjects. After 19 months (median) the investigated variables were analysed for their use in prognosis of recurrent infections and survival.

Results-C3 and C4 concentrations and the haemolytic complement activity of the alternative pathway were decreased in decompensated cirrhotic patients compared with controls $(p<0 \cdot 01)$. Univariate analysis (log rank test) showed that low concentrations ( $\leq$ lower quartile) of C3 $(p<0.001)$ and C3bc $(p<0.05)$, haemolytic complement activity of the alternative pathway $(p<0.01)$ and classic pathway $(p<0.05)$, and decompensated cirrhosis $(\mathbf{p}<0.001)$ were associated with an increased risk of infection and increased mortality. Multivariate (Cox) analysis showed that low C3 concentrations and decompensation of cirrhosis were significant predictors of infections and mortality (p<0.02).

Conclusions-Low serum C3 concentrations and decreased haemolytic complement function predisposes to infection and increased mortality in patients with alcoholic cirrhosis.

(Gut 1997; 40: 544-549)

Keywords: complement, cirrhosis, infection, prognosis.

Bacterial infections often occur in patients with cirrhosis and are a major cause of death in these patients. ${ }^{1}$ Activation of the complement system is pivotal in the host defence against bacterial infections. There are three main effector mechanisms by which complement eliminates bacteria: (1) direct killing by the terminal C5b-9 complement complex (TCC); (2) recruitment of phagocytic cells to sites of infection by release of anaphylatoxins; and (3) generation of opsonins which contribute to immune recognition of microbes. ${ }^{2}$ Intact opsonisation is essential for efficient phagocytosis and subsequent intracellular killing of bacteria. ${ }^{3}$ Consequently, complement deficiencies are associated with recurrent bacterial infections. ${ }^{4}$

Low serum concentrations of complement components, in particular C3 and C4, have been described in patients with alcoholic cirrhosis. $^{5-9}$ These findings are not consistent, ${ }^{10-12}$ but when present, deficiencies of $\mathrm{C} 3$ and $\mathrm{C} 4$ correlate with variables of hepatic synthetic function such as serum albumin and prothrombin time, indicating decreased hepatic synthesis of complement as a cause of these deficiencies. Interestingly, low concentrations of $\mathrm{C} 3$ in cirrhotic ascites ${ }^{13-16}$ as well as low serum concentrations of $\mathrm{C} 3{ }^{16}$ predispose to spontaneous bacterial peritonitis, although the ascitic fluid opsonic activity seems to be a better predictor of the risk of acquiring this type of infection. ${ }^{16}$

In this study we have determined serum concentrations of $\mathrm{C} 3$ and $\mathrm{C} 4$, plasma concentrations of $\mathrm{C} 3 \mathrm{bc}, \mathrm{C} 9$, TCC, and the haemolytic complement activity (classic and alternative pathways) of serum and serum opsonic activity in 77 patients with alcoholic cirrhosis. The purpose was to relate the investigated variables to severity of liver disease and after a follow up period of 19 months (median), to analyse the prognostic significance of these variables for recurrent infection and for survival.

\section{Methods}

\section{PATIENTS}

Seventy seven patients with alcoholic cirrhosis (20 women, 57 men, median age 54 (range 36-78) years) were included prospectively when admitted to the Department of Medicine B, Bispebjerg Hospital, Copenhagen. Fifteen age and sex matched non-alcoholic healthy members of the hospital staff were included as controls (five women, 10 men, median age 52 (range 30-68) years).

All the patients had a history of a minimal daily alcohol intake of $50 \mathrm{~g}$ ethanol for at least five years and presented with clinical signs typical of cirrhosis. In $63(82 \%)$ patients cirrhosis was histologically verified by a liver biopsy performed either previously for inclusion or within four weeks. 
Patients with other liver diseases, primary haematological diseases, autoimmune diseases, or cancer, or those receiving plasma within a week of blood sampling were excluded, as were patients treated with prednisolone or cytotoxic agents.

Based on clinical findings of ascites or hepatic encephalopathy, the patients were divided into compensated $(n=46)$ and decompensated $(n=31)$ groups. Table I gives the clinical and biochemical variables of liver diseases. The presence of actual infection was evaluated by clinical examination at inclusion. Six $(8 \%)$ patients were considered to have present infection, which was bacteriologically proved in five cases - bacteraemia $(n=2)$, urinary tract infection $(n=1)$, and intraabdominal abscess $(n=2)$. In one patient a diagnosis of pneumonia was based on history, clinical examination, and a thoracic radiograph. The patients and controls are part of a study previously described elsewhere. ${ }^{17} 18$ Included in this study are those in whom a complete set of data (C3, C3bc, C4, C9, TCC, haemolytic complement activity (classic and alternative pathways), and serum opsonic activity) was obtained.

Follow up of patients was performed after a median observation period of 19 (range two weeks - 22 months), when all deaths were registered. Furthermore, all infections that had occurred during admission to hospital were registered. Causes of death and information on occurrence of infections during the follow up period were obtained from death certificates and hospital records.

Twenty four $(31 \%)$ of the patients died during the follow up period. Eleven died in liver coma; five died of infections; one of acute alcohol intoxication; one of gastrointestinal bleeding; and one because of a perforated gastric ulcer with peritonitis. In one patient the primary cause of death was registered as "cirrhosis hepatitis"; further information was not available. Four patients were found dead at home with no apparent cause. Necropsy was performed on one of these patients and pulmonary oedema was found to be the primary cause of death. The immediate cause of death could be related to alcoholism or cirrhosis in $20(83 \%)$ patients. Such a relation could neither be verified nor excluded in three $(13 \%)$ of the patients, whereas one (4\%) patient probably died of cardiovascular disease.

TABLE I Clinical and biochemical variables in controls and patients with alcoholic cirrhosis

\begin{tabular}{|c|c|c|c|}
\hline & Control group & $\begin{array}{l}\text { Compensated } \\
\text { cirrhosis group }\end{array}$ & $\begin{array}{l}\text { Decompensated } \\
\text { cirrhosis group }\end{array}$ \\
\hline $\begin{array}{l}\text { No of persons } \\
\text { Encephalopathy } \\
\text { Ascites } \\
\text { Infection } \\
\text { Plasma albumin }(\mathrm{g} / \mathrm{dl}) \\
\text { Plasma PC } \\
\text { Serum AST }(\mathrm{U} / \mathrm{l}) \\
\text { Serum APH }(\mathrm{U} / \mathrm{l}) \\
\text { Serum bilirubin }(\mu \mathrm{mol} / \mathrm{)}) \\
\text { Serum } \gamma \text {-GT }(\mathrm{U} / \mathrm{l})\end{array}$ & $\begin{array}{c}4 \cdot 47(4 \cdot 25-4 \cdot 66) \\
1 \cdot 17(1 \cdot 02-1 \cdot 30) \\
20(18-25) \\
136(109-150) \\
7(6-8) \\
16(10-24)\end{array}$ & $\begin{array}{l}2 \\
3 \cdot 93(3 \cdot 29-4 \cdot 17)^{\star} \\
0 \cdot 76(0 \cdot 58-0 \cdot 86)^{\star} \\
42(32-62)^{\star} \\
307(213-381)^{\star} \\
13(9-21)^{\star} \\
203(87-464)\end{array}$ & $\begin{array}{l}31 \\
8 \\
29 \\
4 \\
2 \cdot 76(2 \cdot 57-3 \cdot 04) \dagger \\
0 \cdot 46(0 \cdot 35-0 \cdot 54)^{\star} \dagger \\
66(40-117)^{\star} \dagger \\
386(197-450)^{\star} \\
36(15-82)^{\star} \dagger \\
147(65-254)\end{array}$ \\
\hline
\end{tabular}

Values of biochemical variables denote the median and quartile ranges; ${ }^{\star} p<0.05$ compared with controls; $t p<0.05$ compared with compensated cirrhotic patients; $P C=$ prothrombin complex; AST=aspartate aminotransferase; APH=alkaline phosphatase; $\gamma-\mathrm{GT}=\gamma$-glutamyl transferase.
ETHICS

The study protocol conformed to the Helsinki Declaration of 1975 and was approved by the local scientific ethics committee.

\section{BLOOD COLLECTION}

Within 24 hours of clinical examination, blood samples were taken into a closed vacutainer system. EDTA treated tubes were immediately cooled on ice, whereas empty tubes were kept at room temperature until the blood was coagulated. The tubes were subsequently centrifuged. EDTA treated plasma and serum were frozen within one hour and stored at $-70^{\circ} \mathrm{C}$ until analysis.

\section{ASSAYS}

\section{$C 3$ and $C 4$}

Concentrations of C3 and C4 were measured in serum by nephelometry (Behringwerke AG, Marburg, Germany). Our standard serum pool (NHS) was calibrated with the international serum standard CRM 470, and contained 1.33 g/l C3, corresponding to $7 \cdot 19 \mu \mathrm{M}$ (MW 185 $\mathrm{kDa}$ ), and $0.25 \mathrm{~g} / \mathrm{l} \mathrm{C} 4$, corresponding to 1.22 $\mu \mathrm{M}(\mathrm{MW} 205 \mathrm{kDa})$.

\section{C9}

C9 was quantified in EDTA treated plasma by an enzyme immunoassay as described previously. ${ }^{19}$ Briefly, ascitic fluid of the native restricted anti-C9 $\mathrm{mAb} M 1$ was used as the coating (diluted 1/10 000). A pool of EDTA treated plasma (NHP) made in parallel with NHS was used as the standard, defining $100 \%$. Samples were diluted 1/5000. A rabbit antiserum to C9 (Behringwerke) and peroxidase linked donkey antibodies to rabbit Ig (Amersham) were used as the detecting system.

\section{$C 3 b c$}

$\mathrm{C} 3 \mathrm{bc}$ denotes the $\mathrm{C} 3$ activation products containing the $\mathrm{C} 3 \mathrm{c}$ moiety $(\mathrm{C} 3 \mathrm{~b}, \mathrm{iC} 3 \mathrm{~b}$, and C3c) and was quantified in EDTA treated plasma by an enzyme immunoassay as described in detail previously. ${ }^{20}$ The assay is based on the use of mAb bH6 which reacts with a neoepitope expressed on $\mathrm{C} 3 \mathrm{bc}$, but not on native $\mathrm{C} 3$. Ascites fluid of bH6 diluted $1 / 10000$ was used as the capture antibody. Zymosan activated serum (ZAS) was made from NHS and used as standard, defining 1000 $\mathrm{AU} / \mathrm{ml}$. The samples were assayed diluted $1 / 300$. A rabbit antiserum to $\mathrm{C} 3 \mathrm{c}$ (Behringwerke) and peroxidase linked donkey antibodies to rabbit Ig (Amersham) were used as detecting antibodies. In ZAS virtually all C3 had been converted to C3bc, but the total C3 content as defined by nephelometry was not significantly different from NHS, indicating that the molar concentration of $\mathrm{C} 3 \mathrm{bc}$ in ZAS corresponded to the molar concentration of C3 in NHS. This fact was used when calculating the $\mathrm{C} 3 \mathrm{bc} / \mathrm{C} 3$ ratio (activated $\mathrm{C} 3 /$ total C3). 
TCC

TCC was quantified in EDTA treated plasma by an enzyme immunoassay as described in detail previously. ${ }^{21}$ The assay is based on the use of mAb aE11 which reacts with a neoepitope expressed on C9 in TCC, but not on native $C 9$. aE11 purified from culture supernatant was used as the capture antibody at a concentration of $1 \mu \mathrm{g} / \mathrm{ml}$. ZAS was used as standard, defining $1000 \mathrm{AU} / \mathrm{ml}$. The samples were assayed diluted 1/10. Subsequently, the anti-C6 mAb 9C4 was used (culture supernatant diluted 1/1000) and then peroxidase conjugated subclass specific goat antimouse IgG1 antibodies diluted 1/4000 (Southern Biotechnology Associates, Inc, Birmingham, AL, USA). The assay was feasible as aE11 is of subclass IgG2a, whereas $9 \mathrm{C} 4$ is of subclass IgG1. As ZAS represents maximal complement activation, a $\mathrm{C} 9$ activation ratio was calculated by dividing sample TCC concentration $(1000 \mathrm{AU} / \mathrm{ml}=100 \%)$ by sample C9 concentration (in \%).

\section{Haemolytic complement pathway}

The haemolytic complement activity of the alternative and classic pathways was measured by a kinetic assay described by Polhill $e t$ al and by Broackle and Pruitt. ${ }^{22}{ }^{23}$ In brief, the optical density at $700 \mathrm{~nm}$ of rabbit erythrocytes (for the alternative pathway) and antibody coated sheep erythrocytes (for the classic pathway) is measured at $37^{\circ} \mathrm{C}$ in a spectrophotometer. As lysis proceeds, there is a decrease in the intensity of scattered light and an increase in transmitted light. The time needed to accomplish $50 \%$ lysis $\left(\mathrm{T}_{1 / 2}\right)$ is measured at a final dilution of $1: 8.6$ for the alternative pathway assay and 1:94 for the classic pathway assay. The haemolytic activity of a serum sample is expressed as a percentage of that of a standard human serum pool, by interpolation on a graph of $T_{1 / 2}$ versus serum concentration in a dilution series of the human serum pool.

\section{Serum opsonic activity}

Briefly, serum was mixed with zymosan particles, human neutrophils, and luminol. As the zymosan particles were opsonised by serum, the particles were phagocytosed by the neutrophils, which at the same time began to produce free oxygen radicals. The radicals reacted with luminol, where upon light was produced. This chemiluminescence reaction was measured in a luminometer (LKB 1250; LKB, Finland) equipped with a thermos for simultaneous measurements of six reactions. Neutrophils from a control person (EDTA treated blood) were isolated by Ficoll/Hypaque gradient centrifugation ${ }^{24}$ and adjusted to $3 \times 10^{6}$ cells $/ \mathrm{ml}$ in Dulbecco's minimum essential medium (DMEM; Boehringer Mannheim, Germany). Neutrophils $(\mu \mathrm{l})$ were mixed with $1250 \mu \mathrm{l}$ DMEM with $0.094 \mu \mathrm{mol} / \mathrm{l}$ luminol (Sigma, St Louis, Missouri, USA) and 10 to 30 $\mu l$ human serum. This mixture was prewarmed to $37^{\circ} \mathrm{C}$, after which $150 \mu \mathrm{l}$ zymosan $(20 \mathrm{mg} / \mathrm{l}$ (Sigma)) was added. The time needed to accomplish a chemiluminescence signal above background was recorded (set to $2 \mathrm{mV}$, equivalent to about $1 \%$ of the maximal signal). In a single logarithmic plot there was a nearly linear negative correlation between the time needed for the signal to reach $2 \mathrm{mV}$ and the concentration of serum. In every run we included three samples from patients $(20 \mu \mathrm{l}$ serum) and a standard curve with 10,20 , and $30 \mu$ lof a pool of normal human serum. The opsonic activity of patient samples was expressed as a percentage of the activity of the human serum pool.

\section{STATISTICS}

The Spearman rank sum test was used for correlating biochemical variables. When comparing plasma concentrations the MannWhitney test was used for two groups and the Kruskal Wallis test for more than two groups. Survival and probability of acquiring infections during the follow up period were estimated by the Kaplan Meier method and differences between groups were analysed by the log rank test. Furthermore, the prognostic relevance for survival and for acquiring infection were investigated with multivariate Cox proportional hazard analysis. A value of $p<0.05$ was regarded as significant.

\section{Results}

Table II gives the assessed complement protein concentrations, the total haemolytic activity of

TABLE II A: Complement protein concentrations, haemolytic complement activity and serum opsonic activity in controls and patients with alcoholic cirrhosis. B: Complement protein concentrations, haemolytic complement activity and serum opsonic activity in patients with alcoholic cirrhosis who had an infection during the follow up period

\begin{tabular}{|c|c|c|c|c|c|}
\hline & \multicolumn{3}{|l|}{$A$} & \multicolumn{2}{|l|}{$B$} \\
\hline & Control (group I) & $\begin{array}{l}\text { Compensated } \\
\text { cirrhosis (group II) }\end{array}$ & $\begin{array}{l}\text { Decompensated } \\
\text { cirrhosis (group III) }\end{array}$ & $\begin{array}{l}\text { Infected during follow up } \\
\text { (group IV) }\end{array}$ & $p$ Value \\
\hline $\begin{array}{l}\text { No of persons } \\
\text { C3 (AU/ml) } \\
\text { C3bc (AU/ml) } \\
\text { C3bc/C3 (\%) } \\
\text { C4 (AU/ml) } \\
\text { C9 (\%) } \\
\text { TCC (AU/ml) } \\
\text { TCC/C9 }(\%) \\
\text { Classic pathway (\%) } \\
\text { Alternative pathway (\%) } \\
\text { Opsonisation (\%) }\end{array}$ & $\begin{array}{l}15 \\
1 \cdot 31(1 \cdot 17-1 \cdot 50) \\
6 \cdot 1(5 \cdot 5-8 \cdot 5) \\
1 \cdot 1(0 \cdot 8-1 \cdot 3) \\
0 \cdot 32(0 \cdot 22-0 \cdot 36) \\
82(70-121) \\
0 \cdot 5(0 \cdot 3-0 \cdot 6) \\
0 \cdot 49(0 \cdot 41-0 \cdot 75) \\
86(71-110) \\
89(81-112) \\
100(76-121)\end{array}$ & $\begin{array}{l}46 \\
1 \cdot 25(1 \cdot 11-1 \cdot 58) \\
11 \cdot 2(8 \cdot 4-13 \cdot 3) \dagger \\
1 \cdot 7(1 \cdot 3-1 \cdot 9) \dagger \\
0 \cdot 26(0 \cdot 20-0 \cdot 34) \\
92(80-128) \\
0 \cdot 5(0 \cdot 3-0 \cdot 8) \\
0 \cdot 44(0 \cdot 28-1 \cdot 13) \\
78(62-110) \\
94(80-110) \\
119(92-137)\end{array}$ & $\begin{array}{l}31 \\
1 \cdot 10(0 \cdot 84-1 \cdot 29)^{\star} \emptyset \\
9 \cdot 3(7 \cdot 8-10 \cdot 7)^{\star} \\
1 \cdot 8(1 \cdot 5-2 \cdot 0) \dagger \\
0 \cdot 20(0 \cdot 16-0 \cdot 25)^{\star} \ddagger \\
95(65-120) \\
0 \cdot 5(0 \cdot 4-1 \cdot 3) \\
0 \cdot 57(0 \cdot 36-1 \cdot 41) \\
74(56-100) \\
82(67-97)^{\star} \dagger \\
95(60-134)\end{array}$ & $\begin{array}{c}14 \\
0 \cdot 93(0 \cdot 83-1 \cdot 32) \\
9 \cdot 0(7 \cdot 3-12 \cdot 4) \\
1 \cdot 9(1 \cdot 6-2 \cdot 1) \\
0 \cdot 21(0 \cdot 16-0 \cdot 26) \\
127(67-148) \\
0 \cdot 5(0 \cdot 2-2 \cdot 5) \\
0 \cdot 47(0 \cdot 33-1 \cdot 53) \\
65(50-89) \\
81(67-97) \\
90(52-139)\end{array}$ & $\begin{array}{l}0 \cdot 02 \\
0 \cdot 03 \\
0 \cdot 0001 \\
0 \cdot 007 \\
0 \cdot 31 \\
0 \cdot 83 \\
0 \cdot 88 \\
0 \cdot 11 \\
0 \cdot 22 \\
0 \cdot 66\end{array}$ \\
\hline
\end{tabular}

Values of biochemical variables denote the median and quartile ranges. ${ }^{\star} p<0.01 ; \nmid p<0.0001$ compared with controls; $\neq p<0.05$ $\oint \mathrm{p}<0.01$ compared with compensated cirrhotics; $\mathrm{p}$ values when comparing group I and IV. 
the classic and alternative pathways, and the opsonic activity of serum.

$\mathrm{C} 3, \mathrm{C} 4$

Serum C3 and C4 concentrations were decreased in decompensated cirrhotic patients compared with controls as well as compensated cirrhotic patients (Table IIA). Concentrations of serum C3 correlated significantly $(p=0.0001)$ with variables of hepatic synthetic function (albumin, $\rho=0.50$ and prothrombin complex (PC), $\rho=0.44)$. Only weak correlations were found with variables of liver injury (bilirubin, $\rho=0.28, p=0.02$ and aspartate aminotransferase, $\rho=-0 \cdot 22$; NS). Serum C4 concentrations correlated with variables of hepatic synthetic function (PC, $\rho=0.55, p=0.0001$ and albumin, $\rho=0.39, p=0 \cdot 0007)$. Furthermore, serum C4 concentrations correlated with variables of liver injury (bilirubin, $\rho=-0.38, p=0.0008$ and aspartate aminotransferase, $\rho=-0 \cdot 24, p=0 \cdot 04$ ).

C3BC, $\mathrm{C} 3 \mathrm{BC} / \mathrm{C} 9$

Plasma C3bc concentrations and in particular the $\mathrm{C} 3 \mathrm{bc} / \mathrm{C} 3$ ratio were increased in both the cirrhosis groups compared with controls. The highest $\mathrm{C} 3 \mathrm{bc} / \mathrm{C} 3$ ratio was found in the decompensated cirrhotic patients (Table II). Furthermore, plasma C3bc concentrations and the $\mathrm{C} 3 \mathrm{bc} / \mathrm{C} 3$ ratio were increased in the infected cirrhotic patients ( $n=6$, median (quartiles) $9 \cdot 6$ $(8 \cdot 8-10 \cdot 7), p=0.01$ and $1.5(1 \cdot 3-1 \cdot 8), p=0.02$ respectively) as well as in the cirrhotic patients without infection ( $\mathrm{n}=71$, median (quartiles) $10.5(7 \cdot 9-12 \cdot 8), \mathrm{p}=0.0002$ and $1.7(1.4-2 \cdot 0)$, $\mathrm{p}=0.0001$, respectively) compared with controls.

C9, TCC, TCC/C9

Plasma C9 and TCC concentrations and the TCC/C9 ratio showed no significant differences when the compensated cirrhosis group, the decompensated cirrhosis group, and the control group were compared (Table II). The highest $\mathrm{C} 9$ and TCC concentrations as well as the highest TCC/C9 ratio were found in the six infected cirrhotic patients (median (quartiles) $124.4(90.8-145.6), 1.2(0.3-1.4)$, and 0.73 $(0.47-1.54)$ respectively), but these concentrations were not significantly different from the controls. The C9 and TCC concentrations as well as the TCC/C9 ratio in the cirrhotic patients without infection $(n=71$ median (quartiles) $91 \cdot 7(69 \cdot 2-118 \cdot 7), 0.5(0 \cdot 3-0 \cdot 8)$, and $0.51(0.34-1.11)$ respectively) were not significantly different from the corresponding concentrations in the infected cirrhotic patients or in the controls.

\section{CLASSIC PATHWAY}

The haemolytic activity of the classic pathway tended to decrease with increasing severity of liver disease, but the differences seen between the compensated cirrhosis group, decompensated cirrhosis group, and the controls did not reach significance (Table IIA). The highest activity was found in the six infected cirrhotic patients (median 99, quartiles 86-102), but these concentrations were neither significantly different from the controls nor from the cirrhotic patients without infection $(n=71$, median 75, quartiles 58-106). No significant correlations were found between the haemolytic activity of the classic pathway and serum C3 or serum C4 concentrations $(\rho=0 \cdot 20$, $\mathrm{p}=0.08$ and $\rho=0 \cdot 19, \mathrm{p}=0 \cdot 10$ respectively).

\section{ALTERNATIVE PATHWAY}

The haemolytic activity of the alternative pathway was significantly lower in the decompensated cirrhotic patients compared with controls as well as compensated cirrhotic patients (Table IIA). No significant differences in haemolytic activity were found when comparing the six infected cirrhotic patients (median 93, quartiles 90-102) with controls and cirrhotic patients without infection $(n=71$, median 90, quartiles 76-105). A highly significant correlation was found between the haemolytic activity of the alternative pathway and serum C3 concentrations $(\rho=0 \cdot 61$, $p=0.0001$, whereas a weaker correlation was found with serum C4 concentrations $(\rho=0 \cdot 38$, $\mathrm{p}=0 \cdot 001$ ).

\section{OPSONISATION}

The serum opsonic activity showed no significant differences between the compensated cirrhosis group, decompensated cirrhosis group, and the control group (Table IIA). No significant differences in opsonic activity were found when comparing the six infected cirrhotic patients (median 117, quartiles 96-130) with controls and cirrhotic patients without infection $(\mathrm{n}=71$, median 109, quartiles 73-137). A weak correlation was found between the serum opsonic activity and serum concentrations of $\mathrm{C} 4(\rho=0 \cdot 28, p=0 \cdot 02)$, but no significant correlation was found with serum C3 concentrations $(\rho=0 \cdot 18, p=0 \cdot 11)$.

FOLLOW UP, INFECTION, AND SURVIVAL

Table IIA gives the assessed complement protein concentrations, the total haemolytic activity of the classic and alternative pathway, and the opsonic activity of serum in the

TABLE III Type of infections in 77 patients with alcoholic cirrhosis during follow up

\begin{tabular}{lll}
\hline & Type of infection & Diagnostic method \\
\hline 1 & Pneumonia & Culture (Streptococcus pneumoniae) \\
2 & Pneumonia & Culture (Streptoccocus pneumoniae) \\
3 & Peritonitis & Culture (Streptococcus pneumoniae, \\
& & Staphylococcus aureus) \\
5 & Pneumonia & Death certificate \\
5 & Septicaemia & Culture (Staphylococcus aureus) \\
7 & Pneumonia & Clinical \\
8 & Pneumonia & Culture (Staphylococcus aureus) \\
9 & Pneumonia & Clinical and radiographic \\
10 & Peritonitis & Clinical and radiographic \\
11 & Otitis media & count greater than 500 $\times 10^{6} / 1$ \\
12 & Cutaneous abcesses \\
13 & Erysipelas & Culture (Streptococcus pneumoniae) \\
14 & Septicaemia & Clinical (Staphylococcus aureus) \\
\hline
\end{tabular}


TABLE IV Predictors of infection in 77 patients with alcoholic cirrhosis estimated by univariate (log rank) statistical analysis

\begin{tabular}{lcl}
\hline & $\begin{array}{l}\text { Lower } \\
\text { quartile }\end{array}$ & $\begin{array}{l}\text { Log rank } \\
\text { (p value) }\end{array}$ \\
\hline C3 (AU/ml) & $1 \cdot 01$ & $0 \cdot 0006$ \\
C3bc (AU/ml) & $7 \cdot 9$ & $0 \cdot 04$ \\
C3bc/C3 (\%) & $1 \cdot 4$ & $0 \cdot 33$ \\
C4 (AU/ml) & $0 \cdot 18$ & $0 \cdot 20$ \\
C9 (\%) & 70.7 & $0 \cdot 34$ \\
TCC (AU/ml) & $0 \cdot 3$ & $0 \cdot 46$ \\
TCC/C9 (\%) & $0 \cdot 34$ & $0 \cdot 11$ \\
Classic pathway (\%) & 59 & $0 \cdot 01$ \\
Alternative pathway (\%) & 77 & 0.005 \\
Opsonisation (\%) & 77 & $0 \cdot 17$ \\
& \multicolumn{2}{c}{ Group size } \\
Decompensation (yes/no) & $31 / 46$ & $0 \cdot 0002$ \\
\hline
\end{tabular}

The patients were divided into groups according to the lower quartile value of the biochemical variables, or to the presence of decompensated cirrhosis.

TABLE V Predictors of death in 77 patients with alcoholic cirrhosis estimated by univariate (log rank) statistical analysis

\begin{tabular}{lcc}
\hline & $\begin{array}{l}\text { Lower } \\
\text { quartile }\end{array}$ & $\begin{array}{c}\text { Log rank } \\
\text { ( } p \text { value) }\end{array}$ \\
\hline C3 (AU/ml) & $1 \cdot 01$ & $0 \cdot 0005$ \\
C3bc (AU/ml) & $7 \cdot 9$ & $0 \cdot 02$ \\
C3bc/C3 (\%) & $1 \cdot 4$ & $0 \cdot 45$ \\
C4 (AU/ml) & $0 \cdot 18$ & $0 \cdot 44$ \\
C9 $(\%)$ & $70 \cdot 7$ & $0 \cdot 28$ \\
TCC $(\mathrm{AU} / \mathrm{ml})$ & $0 \cdot 3$ & $0 \cdot 10$ \\
TCC/C9 $(\%)$ & $0 \cdot 34$ & $0 \cdot 10$ \\
Classic pathway (\%) & 59 & $0 \cdot 0495$ \\
Alternative pathway (\%) & 77 & $0 \cdot 007$ \\
Opsonisation (\%) & 77 & $0 \cdot 17$ \\
& \multicolumn{2}{c}{ Group size } \\
Decompensation (yes/no) & $31 / 46$ & $0 \cdot 0005$ \\
\end{tabular}

The patients were divided into groups according to the lower quartile value of the biochemical variables, or to the presence of decompensated cirrhosis.

patients who had an infection during the follow up period. In particular, these patients had the lowest C3 concentrations of all the cirrhotic patients. Table III gives the type of infections occurring during the follow up period.

Assuming that only patients with severely decreased complement would show an increased susceptibility to infection, the prognostic significance of the investigated variables were analysed using the lower quartile as cut off level. Using univariate analysis (log rank test) low concentrations of $\mathrm{C} 3$ and $\mathrm{C} 3 \mathrm{bc}$, and low levels of classic and alternative pathway haemolytic activity were associated with an increased risk of infection (Table IV) and increased mortality (Table V). The investigated variables were then analysed with multivariate regression analysis (Cox proportional hazard model). Selection of variables for the final Cox models was made using the backward elimination model. ${ }^{25}$ Overall, the final models were highly significant (infection

TABLE VI Serum concentrations and decompensated cirrhosis as predictors of infection and mortality analysed by multivariate (Cox) statistical analysis

\begin{tabular}{|c|c|c|c|c|}
\hline & \multicolumn{2}{|c|}{ Cox: predictor of infection } & \multicolumn{2}{|c|}{ Cox: predictor of mortalit } \\
\hline & $(R R)$ & ( $p$ Value) & $(R R)$ & ( $p$ Value) \\
\hline $\begin{array}{l}\text { C3 (AU/ml) (Lower quartile } 1 \cdot 01 \text { ) } \\
\text { Decompensation (yes/no) (group size 31/46) }\end{array}$ & $\begin{array}{l}3 \cdot 70 \\
6 \cdot 25\end{array}$ & $\begin{array}{l}<0.02 \\
<0.01\end{array}$ & $\begin{array}{l}2.78 \\
3.13\end{array}$ & $\begin{array}{l}<0.02 \\
<0.02\end{array}$ \\
\hline
\end{tabular}

The patients were divided into groups according to the lower quartile value of the serum $\mathrm{C} 3$ concentration, or to the presence of decompensated cirrhosis. Cox RR indicates the relative risk of infection or death during the follow up period of the low value group compared with the high value group, or of the decompensated group compared with the compensated cirrhosis group.
valup model $\mathrm{p}=0.00008$ and survival model $\mathrm{p}=0 \cdot 0002$ ). Decompensation and low C3 concentrations were the only significant predictors of infection and mortality (Table VI).

\section{Discussion}

In the present study of 77 patients with alcoholic cirrhosis we found that serum concentrations of the complement factors $\mathrm{C} 3$ and $\mathrm{C} 4$ and the serum haemolytic complement function decreased with increasing severity of liver disease, correlating with plasma concentrations of known variables of hepatic synthetic function (plasma albumin and certain coagulation factors). Furthermore, evidence of an ongoing complement activation in these patients was found as judged by the plasma concentrations of $\mathrm{C} 3 \mathrm{bc}$ and the $\mathrm{C} 3 \mathrm{bc} / \mathrm{C} 3$ ratio. Thus a combination of decreased synthesis as a result of compromised liver function and increased consumption due to complement activation is a probable cause of the low serum concentrations of $\mathrm{C} 3$ and $\mathrm{C} 4$ and the impaired haemolytic activity of complement seen in these patients. A possible cause of the complement activation is the increased endotoxin load in patients with alcoholic liver disease due to impaired hepatic clearance of endotoxins derived from the gut, ${ }^{26-28}$ but deficiencies of complement system regulatory proteins may also be of importance. ${ }^{9}$ The plasma concentration of $\mathrm{C} 9$, another liver derived complement factor, was not decreased, indicating a different regulatory pattern than for $\mathrm{C} 3$ and C4.

Patients with alcoholic liver cirrhosis are prone to infections and recent studies have shown an association between low concentrations of $\mathrm{C} 3$ in cirrhotic ascites and occurrence of spontaneous bacterial peritonitis. ${ }^{13-15}$ The decrease in complement function leaves the patients particularly vulnerable to infection, because complement is assumed to be crucial in the primary defence against bacteria. ${ }^{2-4}{ }^{29}$ Interestingly, the present study demonstrates the prognostic importance of complement in patients with alcoholic cirrhosis in terms of an association between low serum concentrations of $\mathrm{C} 3$ and haemolytic function (in particular of the alternative pathway) with an increased risk of acquiring infections during the follow up period and an increased mortality.

The opsonic activity of serum was not impaired in the cirrhotic patients and did not correlate with severity of liver disease. Accordingly, no prognostic significance for recurrent infections or mortality was found. Only weak correlations were found between the opsonic activity of serum and the serum C3 and $\mathrm{C} 4$ concentrations, probably because the total opsonic activity of serum was assessed, thus including the activity of other opsonising proteins such as the immunoglobulins. The differences in prognostic significance of opsonic activity and complement function illustrates the importance of the complement system not only as opsonising serum proteins, but as a complex system with several immuno- 
inflammatory properties which include recruitment of phagocytic cells by generation of anaphylatoxins and direct bacterial killing by the TCC.

In conclusion, low serum $\mathrm{C} 3$ concentrations and decreased haemolytic complement activity, particularly of the alternative pathway, predisposes to infection and increased mortality in patients with alcoholic cirrhosis. A combination of decreased synthesis as a result of compromised liver function and increased consumption due to complement activation is a probable cause of the low serum concentrations of $\mathrm{C} 3$ and $\mathrm{C} 4$ and the impaired haemolytic activity of complement seen in these patients.

We thank the Department of Clinical Chemistry, Bispebjerg Hospital, Copenhagen, Denmark, for invaluable help and support. Excellent technical assistance was provided by Bente Falang Hoaas, Institute of Immunolgy and Rheumatology, University of Oslo, Oslo, Norway.

1 Wyke RJ. Problems of bacterial infection in patients with liver disease. Gut 1987; 28: 623-41.

2 Frank MM. Complement in the pathophysiology of human disease. N Engl ₹ Med 1987; 316: 525-30.

3 Horwitz M. Phagocytosis of microorganisms. Rev Infect Dis 1982; 4: 104-23.

4 Agnello V. Complement deficiency states. Medicine 1978; 57: 1-23.

5 Finlayson NDC, Krohn K, Fauconnet MH, Anderson KE. Significance of serum complement levels in chronic liver disease. Gastroenterology 1972; 63: 653-9.

6 Kourilsky O, Leroy C, Peltier AP. Complement and liver cell function in 53 patients with liver disease. $\mathrm{Am} \mathrm{f} \mathrm{Med}$ 1973; 55: 783-90.

7 Potter BJ, Trueman AM, Jones EA. Serum complement in chronic liver disease. Gut 1973; 14: 451-6.

8 Potter BJ, Elias E, Fayers PM, Jones EA. Profiles of serum complement in patients with hepatobiliary diseases. Digestion 1978; 18: 371-83.

9 Ellison RT III, Horsburgh R Jr, Curd J. Complement levels in patients with hepatic dysfunction. Dig Dis Sci 1990; 35: 231-5.

10 Fox RA, Dudley FJ, Sherlock $S$. The serum concentration of the third component of complement $\beta 1 \mathrm{C} / \beta 1 \mathrm{~A}$ in liver disease. Gut 1971; 12: 574-8.

11 Munoz LE, De Villiers D, Markham D, Whaley K, Thomas HC. Complement activation in chronic liver disease. Clin Exp Immunol 1982; 47: 548-54.

12 Gluud C, Jans H. Circulating immune complexes and complement concentrations in patients with alcoholic complement concentrations in patients

13 Such J, Guarner C, Enriquez J, Rodriguez JL, Seres I, Vilardell F. Low $\mathrm{C} 3$ in cirrhotic ascites predisposes to spontaneous bacterial peritonitis. $\mathcal{f}$ Hepatol 1988; 6: $80-4$.
14 Runyon BA. Patients with deficient ascitic fluid opsonic activity are predisposed to spontaneous bacterial peritonitis. Hepatology 1988; 8: 632-5.

$15 \mathrm{Mal}$ F, Pham Huu T, Bendahou M, Trinchet JC, Gardier M, Hakim J, et al. Chemoattractant and opsonic activity in ascitic fluid. A study in 47 patients with cirrhosis or malignant peritonitis. $f$ Hepatol 1991; 12: cirrhosis

16 Andreu M, Sola R, Sitges-Serra A, Alia C, Gallen M Vila MC, et al. Risk factors for spontaneous bacterial peritonitis in cirrhotic patients with ascites. Gastroenterology 1993; 104: 1133-8.

17 Homann C, Garred P, Hasselqvist P, Graudal N, Thiel S Thomsen $\AA \mathrm{C}$. Mannan-binding protein and complement dependent opsonization in alcoholic cirrhosis. Liver 1995 15: $39-44$.

18 Homann C, Garred P, Graudal N, Hasselqvist P, Christiansen M, Fagerhol MK, et al. Plasma calprotectin: a new prognostic marker of survival in alcohol-induced cirrhosis. Hepatology 1995; 21: 979-85.

19 Mollnes TE, Tschopp J. A unique epitope exposed in native complement component $\mathrm{C} 9$ and hidden in the terminal SC5b-9 complex enables selective detection and
quantification of non-activated C 9 . F Immunol Methods quantification of no 1987 ; 100: $215-21$.

20 Garred P, Mollnes TE, Lea T. Quantification in enzymelinked immunosorbent assay of a C3 neoepitope expressed on activated human complement factor C3. Scand f Immunol 1988; 27: 329-35.

21 Mollness TE, Redl H, Høgåsen K, Bengtsson A, Garred P, Speilberg $\mathrm{L}$, et al. Complement activation in septic baboons detected by neoepitope specific assays for $\mathrm{C} 3 \mathrm{~b} /$ iC $3 b / C 3 c, C 5 a$ and the terminal C5b-9 complement complex (TCC). Clin Exp Immunol 1993; 91: 295-300.

22 Polhill RB Jr, Pruitt KM, Johnston RB Jr. Kinetic assessment of alternative complement pathway activity in a hemolytic system. I. Experimental and mathematical analyses. F Immunol 1978; 121: 363-70.

23 Broackle RJ, Pruitt KM. A convenient method for the study of anticomplementary substances in biological fluids. In: Peeters $\mathrm{H}$, eds. Protides of the biological fluids. Oxford: Pergamon Press, 1974; 21: 613-7.

24 Ferrante A, Thong YH. A rapid one-step procedure for purification of mononuclear and polymorphonuclear leucocytes from human blood using a modification of the Hypaque/Ficoll technique. F Immunol Methods 1978; 24: 389-93.

25 Christensen E. Multivariate survival analysis using Cox's regression model. Hepatology 1987; 7: 1346-58.

26 Lumsden AB, Henderson JM, Kutner MH. Endotoxin levels by chromogenic assay in portal, hepatic and peripheral venous blood in patients with cirrhosis. Hepatology 1988; 8: 232-6.

27 Bode C, Kugler V, Bode JC. Endotoxemia in patients with alcoholic and non-alcoholic cirrhosis and in subjects with no evidence of chronic liver disease following acute alcohol excess. F Hepatol 1987; 4: 8-14.

28 Fukui H, Brauner B, Bode JC, Bode C. Plasma endotoxin concentrations in patients with alcoholic and nonalcoholic liver disease: reevaluation with an improved chromogenic assay. $₹$ Hepatol 1991; 12: 162-9.

29 Wessels MR, Butko P, Ma MH, Warren HB, Lage AL, Carroll MC. Studies of group B streptococcal infection in mice deficient in complement component $\mathrm{C} 3$ and $\mathrm{C} 4$ demonstrate an essential role for complement in both innate and acquired immunity. Proc Natl Acad Sci USA 1995; 92: 11490-4. 